\title{
Initial documented rhythm as a predictor of survival- to-discharge rate after in-hospital cardiac arrest in a tertiary care referral institute, South India: an observational study
}

\author{
Surendar Ravipragasam ${ }^{1 *}$, Deepika Chandar², Vinay R Pandit ${ }^{1}$ \\ 'Department of Emergency Medicine, Jawaharlal Institute of Postgraduate Medical Education and Research, Puducherry, India \\ 2Department of Preventive and Social Medicine, Jawaharlal Institute of Postgraduate Medical Education and Research, Puducherry, \\ India
}

\author{
Received: 5 September 2019 \\ Accepted: 7 December 2019 \\ Published online: 16 December \\ 2019 \\ *Corresponding author: Surendar \\ Ravipragasam, \\ Address: no 21, second cross, Mohan \\ Nagar, Pondicherry. \\ Tel: 08056302998 \\ Email: drsurendar18@gmail.com \\ Competing interests: None. \\ Funding information: None. \\ Citation: Ravipragasam S, Chandar \\ D, Pandit VR. Initial documented \\ rhythm as a predictor of survival- \\ to-discharge rate after in-hospital \\ cardiac arrest in a tertiary care \\ referral institute, South India: an \\ observational study. Journal of \\ Emergency Practice and Trauma \\ 2020; 6(1): 23-27. doi: 10.15171/ \\ jept.2019.23.
}

\begin{abstract}
Objective: Survival-to-discharge rates following in-hospital cardiac arrest (IHCA) patients remain significantly low. The use of initial documented cardiac rhythm as predictor of Survival-to-discharge is still unclear. This study aimed to assess whether the initial documented rhythm can be used as a predictor of survival-to-discharge following IHCA in an emergency department of the tertiary care referral institute, south India.

Methods: This observational study was conducted for six months from January to June 2017 among all patients above 12 years, with witnessed cardiac arrest after arrival at the emergency department. After obtaining informed consent from the patients' caregivers, data of socio-demographic details, previous relevant medical history, initial documented rhythm, neurologic status and survival-to-discharge were collected and analyzed.

Results: The mean age of participants was $50 \pm 17.15$ years. Of the 252 study participants, $77.4 \%$ had non-shockable and $22.6 \%$ had shockable rhythm as initial documented rhythm. The overall survival-to-discharge rate was $17.5 \%(n=44)$ in our study. The overall proportion of participants who survived to discharge after IHCA was higher among participants with shockable rhythm $(16 / 57,28 \%)$ in comparison to participants with non-shockable rhythm (28/195, 14.3\%). These differences were found to be statistically significant. Among the patients with shockable rhythm, $61.1 \%$ had good cerebral performance.

Conclusion: Survival-to-discharge rates after IHCA can be predicted based on the initial documented cardiac rhythm. Early identification of patients with impending cardiac arrest and providing prompt management of patients with cardiac arrest will improve the survival rates significantly.

Keywords: In-hospital cardiac arrest, Predictors of survival rate, India
\end{abstract}

\section{Introduction}

Survival-to-discharge rates following in-hospital cardiac arrest (IHCA) patients remain significantly low (1). Globally, the commonest cause of death of patients in the emergency department (ED) is cardiac arrest (2). The survival-to-discharge rates following IHCA range from $7 \%$ to $26 \%$ (1). Several factors play an important role in the survival of patients following cardiac arrest. Age, gender of the patient, associated co-morbidities, in-hospital or out of hospital cardiac arrest are some preceding prognostic factors in determining the survival rates of the patient (3). The initial documented rhythm, quality of the resuscitation, intervals between multiple arrests, and duration of events are some of the intra-arrest factors that will influence the survival outcomes. Among the factors involved in survival outcome of the cardiac arrest patients, the favorable outcome have been found to be associated with, witnessed cardiac arrest, short duration between collapse and initiation of resuscitation, short duration of arrest and larger time interval between arrests in-case of multiple arrests (4-6). The relationship between the initial documented cardiac rhythm and the survival-to-discharge rate has been documented in some studies $(3,7)$. There is scant evidence concerning the relationship between initial documented rhythms and survival-to-discharge rates after IHCA. Therefore, this study aims to determine whether initial documented rhythm can be used as a predictor of survival-to-discharge rates following IHCA in the ED of a 
tertiary care referral institute in South India.

\section{Methods}

This observational study was conducted prospectively for a period of 6 months from January to June 2017 in the ED of a tertiary care hospital in South India. This hospital has an average of 350 emergency cases per day. We included individuals aged $>12$ years, who sustained cardiac arrest after reaching and before leaving the ED, in our study. Patients who had unwitnessed cardiac arrest or who had prior history of cardiac arrest before arriving to the ED, and those who did not have documentation of initial rhythm were excluded from our study. Also, patients without caregivers were excluded from our study. The CPR was done according to American Heart Association (AHA) Guidelines 2016 and all the ED doctors were ACLS (Advanced Cardiac Life Support) certified. After obtaining informed consent from the patients' caregivers, data of socio-demographic details, previous relevant medical history, initial documented rhythm, neurologic status and survival-to-discharge of the patients were collected and entered in EpiData Manager software version 2.0. All analyzes were done using STATA software version 14.1 for Windows (StataCorp, College Station, Texas, USA). Ethical clearance was obtained from the ethics committee before conducting the study.

Definition of cardiac arrest used in our study was the cessation of cardiac mechanical activity confirmed by the absence of detectable pulse, unresponsiveness and/or apnoea (agonal respirations). In case the patient suffered multiple cardiac arrests, only the initial in-hospital arrest at the ED was taken for analysis. The initial documented rhythms were classified as Ventricular fibrillation (VF), pulseless ventricular tachycardia $(\mathrm{VT}(\mathrm{p}))$, pulseless electrical activity (PEA), and asystole.

The sample size was estimated to be 188 individuals based on the expected number of patients with shockable rhythm as $14.27 \%$ (8), with the alpha level at 0.05 and absolute precision 5\% using OpenEpi version 3.01. Total sample size of 207 was estimated after adding $10 \%$ of nonresponse rate.

\section{Results}

A total of about 63180 patients were admitted to the ED of this tertiary care hospital during a period of 6 months. Among this batch, 252 participants had witnessed IHCA and met all inclusion criteria and were included in our study.

The mean age of participants was $50 \pm 17.15$ years with the range of 12-92 years. The majority of participants were in the age group of $41-60$ years (44.4\%) and there was a slight male preponderance $(54.4 \%)$. The patients had conditions such as breathlessness (29\%), chest pain $(20.2 \%)$, trauma (17.5\%) and other complications (33.3\%). About $81.3 \%$ of participants had comorbidities including diabetes diabetes $(\mathrm{n}=41 ; 16.2 \%)$, hypertension $(\mathrm{n}=35 ; 13.8 \%)$, both diabetes and hypertension $(\mathrm{n}=27 ; 10.7 \%)$, ischemic heart disease $(\mathrm{n}=37 ; 14.6 \%), \operatorname{COPD}(\mathrm{n}=22 ; 8.7 \%)$, malignancy $(\mathrm{n}=25$; 9.9\%), and others $(\mathrm{n}=18 ; 7.1 \%)$ (Table 1$)$.

Of the 252 study participants, $77.4 \%$ had non-shockable rhythm and $22.6 \%$ had shockable rhythm. About 136 (54\%) patients had initial rhythm as PEA. Ventricular tachycardia $(n=27 ; 10.7 \%)$ was the least reported initial rhythm among our study population (Figure 1). The overall survival-to-discharge rate was $17.5 \%(n=44)$ in our study (Figure 2).

Among participants with shockable rhythm, 30 (30/57, $52.6 \%)$ cases had VF and $27(27 / 57,47.4 \%)$ cases had VT (P). Of participants with VF, $22(22 / 30,73.3 \%)$ cases attained ROSC but $7(7 / 30,23.3 \%)$ cases survived to discharge. The cases who had initial rhythm as VT (P) 27 (47.4\%), have almost attained better ROSC (26/27, 96.3\%) and survived to discharge rate was also higher (9/27, 33.3\%). Among shockable rhythm patients, VT (P) (33.3\%) had better survival compared to VF $(23.3 \%)$

Among patients with non-shockable rhythm, 136 (136/195, 69.7\%) had PEA and 59 (59/195, 30.2\%) had asystole as

Table 1. Baseline characteristics of study participants $(n=252)$

\begin{tabular}{|c|c|c|}
\hline Variable & Category & No. (\%) \\
\hline \multirow{4}{*}{$\begin{array}{l}\text { Age }(y) \\
\text { Mean }=50 \pm 17.15\end{array}$} & $<20$ & $12(4.8)$ \\
\hline & $21-40$ & $65(25.8)$ \\
\hline & $41-60$ & $112(44.4)$ \\
\hline & $>60$ & $63(25)$ \\
\hline \multirow{2}{*}{ Gender } & Male & $137(54.4)$ \\
\hline & Female & 115 (45.6) \\
\hline \multirow{6}{*}{ Chief complaints } & Breathlessness & $73(29)$ \\
\hline & Chest pain & $51(20.2)$ \\
\hline & Trauma & 44 (17.5) \\
\hline & Fever & $37(14.7)$ \\
\hline & Poisoning & $24(9.5)$ \\
\hline & Others $^{*}$ & $23(9.1)$ \\
\hline \multirow{2}{*}{ Co-morbidity } & Present & $205(81.3)$ \\
\hline & Absent & 47 (18.7) \\
\hline
\end{tabular}

*Abdominal pain, hematemesis, giddiness, vomiting, palpitations, sweating.

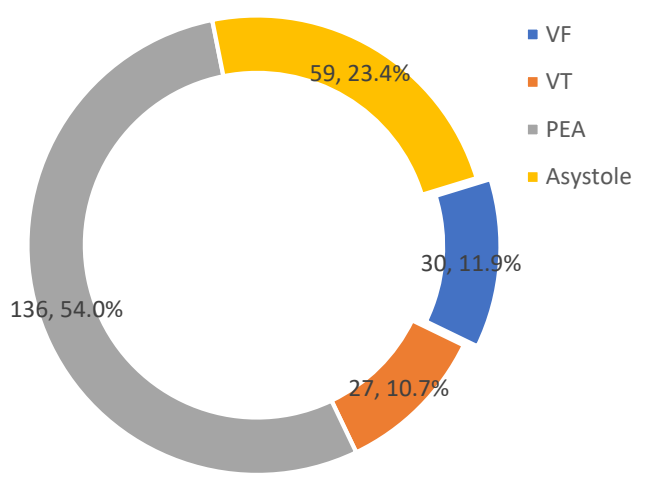

Figure 1. Initial documented rhythm of the participants $(n=252)$. 


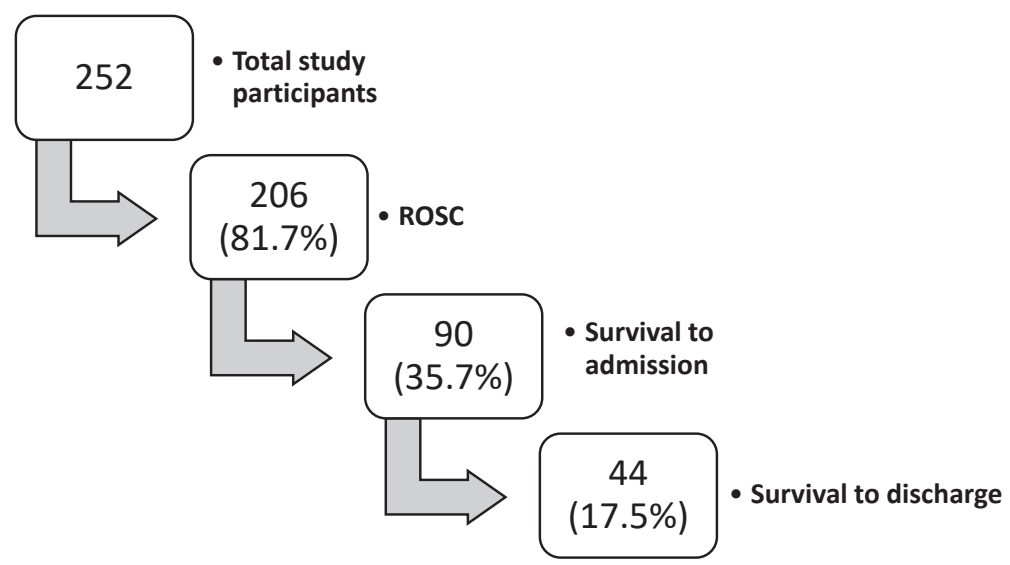

Figure 2. Survival to discharge rate following In-hospital cardiac arrest.

initial rhythm following CPR. Among participants who had PEA as initial rhythm, 107 (109/136, 80.1\%) attained ROSC and only 18 (18/136, 13.2\%) survived to discharge. In participants with asystole as initial rhythm, $51(51 / 59$, $86.4 \%)$ attained ROSC, of which 10 (10/59, 16.9\%) survived to discharge. Thus, among the patients with nonshockable rhythms, survival-to-discharge was better with asystole as initial rhythm.

Though majority of study participants had non-shockable rhythm as initial rhythm after CPR, the overall proportion of participants who survived to discharge after IHCA was higher among participants with shockable rhythm (16/57, $28 \%$ ) in comparison to participants with non-shockable rhythm (28/195, 14.3\%).

Thus, there was significant difference in the survivalto-discharge rate among the patients based on the initial documented rhythm (Table 2 and Figure 3). The neurological status of the patients who survived-todischarge was assessed at the time of discharge using cerebral performance category (CPC) scores (1-4) (9). Among the patients with shockable rhythm, 61.1\% had good cerebral performance. Significant difference was found in the neurological outcome of the patients, with shockable rhythm having better neurological outcome compared to non-shockable rhythm (Table 3).

\section{Discussion}

In our study, $77.4 \%$ of patients had non-shockable rhythm (PEA: 54\%, asystole: $23.4 \%$ ) and 22.6\% had shockable rhythm (VF: 11.9\% and pVT: 10.7\%). Different studies have also reported comparable findings. Johnson et al (8) reported that $14.27 \%$ of patients sustained VF/VT and $85.72 \%$ had either asystole or PEA. Girotra et al (7) reported that $20.7 \%$ of patients had ventricular fibrillation or pulseless ventricular tachycardia and $79.3 \%$ had asystole or PEA as the initial rhythm. Also, Meaney et al (5) reported that among the patients with cardiac arrest, $24 \%$ had shockable rhythm and $76 \%$ had non-shockable rhythm. Thus, we can assume that although the study settings and criteria are different, but all the studies have reported non-shockable rhythm as the most common initial documented rhythm following resuscitation.

Table 2. Initial documented rhythm and survival-to-discharge rate among the study participants $(n=252)$

\begin{tabular}{|c|c|c|c|c|}
\hline \multirow[b]{2}{*}{ Variable } & \multirow[b]{2}{*}{$\begin{array}{c}\text { Category } \\
\text { (n) }\end{array}$} & \multicolumn{2}{|c|}{ Survival to discharge } & \multirow[b]{2}{*}{$P$ value } \\
\hline & & $\begin{array}{c}\text { Yes } \\
\text { No. (\%) }\end{array}$ & $\begin{array}{c}\text { No } \\
\text { No. (\%) }\end{array}$ & \\
\hline \multirow{4}{*}{ Initial recorded rhythm } & VF (30) & $7(23.3)$ & $23(76.7)$ & \multirow{4}{*}{0.05} \\
\hline & $\mathrm{VT}(\mathrm{P})(27)$ & $9(33.3)$ & $18(66.4)$ & \\
\hline & PEA (136) & $18(13.2)$ & $118(86.7)$ & \\
\hline & Asystole (59) & $10(16.9)$ & $49(83.1)$ & \\
\hline
\end{tabular}

Table 3. Neurological status of the patients who survived to discharge based on the initial documented rhythm ( $\mathrm{n}=44$ )

\begin{tabular}{lcc}
\hline Variable & Shockable rhythm & Non-shockable rhythm \\
No. (\%) & No. (\%) & $7(38.9)$ \\
\hline Good cerebral performance & $11(61.1)$ & $10(83.3)$ \\
Mild neurological deficit & $2(16.6)$ & $6(85.7)$ \\
Moderate neurological deficit & $1(14.3)$ & $5(71.4)$ \\
Vegetative state & $2(28.6)$ & 0.03 \\
\hline
\end{tabular}




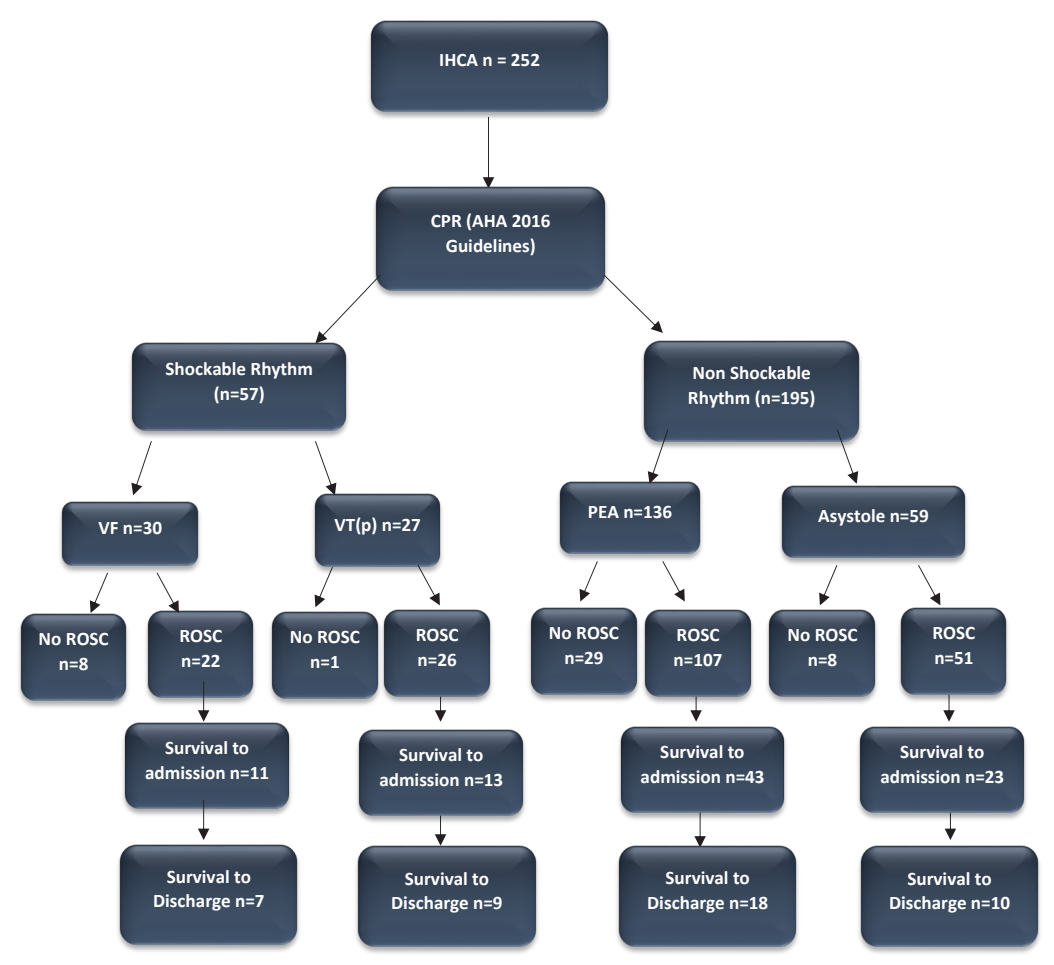

Figure 3. The relationship between initial documented rhythm and survival to discharge rate.

Conversely, in a study regarding the survival-to-discharge rates following out of hospital cardiac arrest (OHCA), VF/ VT was reported as common documented rhythm (10). This decreased prevalence of VF/VT in IHCA compared to OHCA may be due to the difference in pathophysiology. The mechanism of cardiac arrest following IHCA will be hypoxia or hypotension which will present with nonshockable rhythms $(11,12)$.

The survival-to-discharge following IHCA in our study was $17.5 \%$. This proportion is slightly higher compared to the results of Johnson et al (8) where the survival-todischarge rate was only $10 \%$. However, Sandorini et al (3) has reported that the survival-to-discharge rates following IHCA usually vary widely between $0 \%-42 \%$, with most common range beings from $15 \%-20 \%$. Our study also has the value that lies within this range $(17.4 \%)$. The reason for such differences across several studies is due to the fact that the survival rates depend on several factors such as pre-arrest prognostic indicators, quality of the CPR delivered to the patient, associated patient conditions and also post-arrest care following resuscitation.

On comparing the survival rates based on the initial documented rhythm, it can be seen from our study that the patients with shockable rhythms (28\%) had better survival compared to patients with non-shockable rhythm (14.3\%) as initial documented rhythm following resuscitation. This finding is similar to the findings of Johnson et al (8), where they also reported that survival-to-discharge is higher when the initial documented rhythm is either VF/VT. In a systematic review done by Sandorini et al (3), it has been reported that the survival-to-discharge rates are higher with initial documented rhythm as shockable rhythm. Also, they have reported that the survival-todischarge rate will range between $18 \%-64 \%$ in shockable rhythm and between $1.4 \%-14 \%$ in non-shockable rhythm as initial documented rhythm. These findings are very much comparable to the findings from our study which indicates that the survival-to-discharge rates will depend on the initial documented rhythm and it is better with shockable rhythms, irrespective of the study settings, study participants or other associated factors predicting the outcome of cardiac arrest. Among the non-shockable rhythms, patients with asystole (16.9\%) had better survival compared to patients with PEA (13.2\%). This finding differs from the results reported by Johnson et al(8) where survival to hospital discharge was better in PEA (11.75\%) than asystole (7.14\%). Holmgren et al (13) have suggested that there is a decline in the proportion of patients presenting with shockable rhythm among OHCA, however, the proportion of patients surviving from shockable rhythms still remained high disproving the assumption that the decline in proportion of patients with shockable rhythms will thereby reduce the survival rates.

The neurological status of the patients who survived to discharge was better among patients with shockable rhythm. Girotra et al (7) reported that $50.8 \%$ of patients with VF/VT had good cerebral activity which was comparable to our study findings, where the proportion was $61.1 \%$. Johnson et al(8) have also documented that the patients with shockable rhythms have better survival outcomes. 


\section{Conclusion}

Survival-to-discharge rates following IHCA can be predicted based on the initial documented cardiac rhythm. About two-thirds of our study participants reported non-shockable rhythms as initial documented rhythm. However, the proportion of patients survived to discharge was higher among the patients with shockable rhythms. The neurological outcomes were poor among the patients with non-shockable rhythms. The proportion of survivors following IHCA with shockable rhythms is consistent over decades. Early identification of patients with impending cardiac arrest, and providing prompt management of patients with cardiac arrest will improve the survival rates significantly. Focused interventions can be brought up in these areas thereby improving the overall survival-to-discharge rates following IHCA.

\section{Authors' contributions}

All authors contributed substantially in this study concerning idea generation, designing as well as conducting the research. Data collection, entry, and analysis were done by the first and second authors. All authors contributed equally in writing and revising of this manuscript. All authors are accountable for the accuracy and integrity of this work and have read and approved this manuscript for publication.

\section{Ethical Issues}

This study was approved by the Institute Ethics CommitteeHuman studies, JIPMER, Pondicherry (Approval no JIP/ IEC/2015/23/801 and Approval date 03-03-2016).

\section{Acknowledgement}

We would like to acknowledge all the study participants, workers, other resident doctors and the intern doctors working in the Emergency department for their contribution in successful completion of this study.

\section{References}

1. Ehlenbach WJ, Barnato AE, Curtis JR, Kreuter W, Koepsell TD, Deyo RA, et al. Epidemiologic study of in-hospital cardiopulmonary resuscitation in the elderly. N Engl J Med 2009; 361(1): 22-31. doi: 10.1056/NEJMoa0810245.

2. Deo R, Albert CM. Epidemiology and genetics of sudden cardiac death. Circulation 2012; 125(4): 620-37. doi: 10.1161/circulationaha.111.023838.

3. Sandroni C, Nolan J, Cavallaro F, Antonelli M. In-hospital cardiac arrest: incidence, prognosis and possible measures to improve survival. Intensive Care Med 2007; 33(2): 237 45. doi: 10.1007/s00134-006-0326-z.

4. Cooper S, Janghorbani M, Cooper G. A decade of inhospital resuscitation: outcomes and prediction of survival? Resuscitation 2006; 68(2): 231-7. doi: 10.1016/j. resuscitation.2005.06.012.

5. Meaney PA, Nadkarni VM, Kern KB, Indik JH, Halperin HR, Berg RA. Rhythms and outcomes of adult in-hospital cardiac arrest. Crit Care Med 2010; 38(1): 101-8. doi: 10.1097/CCM.0b013e3181b43282.

6. Brady WJ, Gurka KK, Mehring B, Peberdy MA, O'Connor RE. In-hospital cardiac arrest: impact of monitoring and witnessed event on patient survival and neurologic status at hospital discharge. Resuscitation 2011; 82(7): 845-52. doi: 10.1016/j.resuscitation.2011.02.028.

7. Girotra S, Nallamothu BK, Spertus JA, Li Y, Krumholz HM, Chan PS. Trends in survival after in-hospital cardiac arrest. N Engl J Med 2012; 367(20): 1912-20. doi: 10.1056/ NEJMoa1109148.

8. Johnson S, Nileshwar A. Initial rhythm and outcome of in-hospital adult cardiac arrest in a tertiary care hospital. Indian Journal of Respiratory Care 2014; 3(1): 421-5.

9. Afshar F. Brain Failure \& Resuscitation. J R Soc Med 1982; 75(6): 485.

10. Bayés de Luna A, Coumel P, Leclercq JF. Ambulatory sudden cardiac death: mechanisms of production of fatal arrhythmia on the basis of data from 157 cases. Am Heart J 1989; 117(1): 151-9. doi: 10.1016/0002-8703(89)90670-4.

11. Herlitz J, Bång A, Ekström L, Aune S, Lundström G, Holmberg S, et al. A comparison between patients suffering in-hospital and out-of-hospital cardiac arrest in terms of treatment and outcome. J Intern Med 2000; 248(1): 53-60. doi: 10.1046/j.1365-2796.2000.00702.x.

12. Peberdy MA, Kaye W, Ornato JP, Larkin GL, Nadkarni $\mathrm{V}$, Mancini ME, et al. Cardiopulmonary resuscitation of adults in the hospital: a report of 14720 cardiac arrests from the National Registry of Cardiopulmonary Resuscitation. Resuscitation 2003; 58(3): 297-308. doi: 10.1016/s03009572(03)00215-6.

13. Holmgren C, Bergfeldt L, Edvardsson N, Karlsson T, Lindqvist J, Silfverstolpe J, et al. Analysis of initial rhythm, witnessed status and delay to treatment among survivors of out-of-hospital cardiac arrest in Sweden. Heart 2010; 96(22): 1826-30. doi: 10.1136/hrt.2010.198325. 